\title{
SMART CARS AS A SOLUTION FOR OVERPOPULATION
}

\author{
Jelena Pisarov* \\ Óbuda University, Doctoral School on Safety and Security Sciences \\ Budapest, Hungary \\ DOI: 10.7906/indecs.20.1.2 \\ Received: 30 January 2021. \\ Regular article \\ Accepted: 11 November 2021.
}

\section{ABSTRACT}

The latest citizen census data shows that the world's largest cities experienced a population growth last year. As migrations continue, cities will need to work harder and more efficiently to keep up with the impact of the growing population. Because of this, smart cities will set standards in major metropolitan areas around the world.

Self-driving cars would be the solution for overpopulated cities, where citizens will have fast, comfortable, economical, safe, and secure vehicles at their disposal, which allow them to effortlessly reach their destinations on time with the help of the $5 \mathrm{G}$ network.

The next mobile revolution is upon us, with autonomous vehicles heralded as a new element of road traffic. Using cameras and sensors to process road and traffic data in real-time, these vehicles also exchange information with each other and traffic infrastructure, relieving the driver of numerous tasks. Therefore, besides improving the safety of road traffic, autonomous vehicles will bring significant changes to the society we know today.

\section{KEY WORDS}

autonomous vehicles, smart cities, overpopulation, IoT, car sharing

\section{CLASSIFICATION}

ACM: 10002951

JEL: $\quad 018$ 


\section{A DEFINITION OF AUTONOMOUS DRIVING}

The word 'automobile' originates as a blend of the Greek autòs, which means 'self' or 'personal', and the Latin mobilis, meaning 'mobile'. The idea behind this portmanteau was that the carriage, or more accurately, the vehicle is now mobile without horse-power.

However, the author failed to recognize that the absence of horses meant an irrevocable loss of autonomy. Trained and dressed, horses learned themselves (auto-learning) to avoid obstacles on the road, and there were countless cases of 'autonomous drives' when a horse returned a carriage safely home, even in the night, fog, or adverse weather conditions, if the driver was indisposed to continue the journey. Without governance, horses would at least bring the carriage to a safe-mode, grazing their fill of grass on the roadside. Contemporary efforts of the automotive industry are directed to recover some of the lost autonomy and in many ways, rise above this historic example.

Using a special perception of Kant's theory, autonomy is defined as "self-determination within a superordinate (moral) law". In autonomous vehicles, people override the moral law by programming the vehicle's behaviors and responses. This way, the vehicle needs to make continual decisions about what to do in traffic, within the boundaries and specifics of the regulations and prohibitions with which it was coded.

\section{WHAT MAKES A CAR SMART?}

Autonomous vehicles are based on a three-phase design, known as 'sense-plan-act' which is used in many robotic systems. However, instead of performing a series of simple tasks, autonomous vehicles need to navigate complex and dynamic driving environments. To achieve this, smart cars are equipped with a range of sensors, cameras, and radars that collect raw data from the surrounding environments. This data is then processed, while the software recommends the appropriate driving actions and responses [1-5].

\section{CONNECTIVITY IS THE KEY}

With the current population growth rates, it is estimated that by 2050 , congestion and commute times are expected to increase three times, costs of transportation four times, and carbon emissions up to five times the current level. The only viable solution is to transform the traditional city concept into a smart city, where connectivity and automated mobility provide an invisible underlying infrastructure. Apart from empowering local governments to take part in innovative solutions, offering nation-level financial aid, and embracing new technologies, one of the critical changes in developing smart cities is the advent of autonomous driving technology, Figure 1.
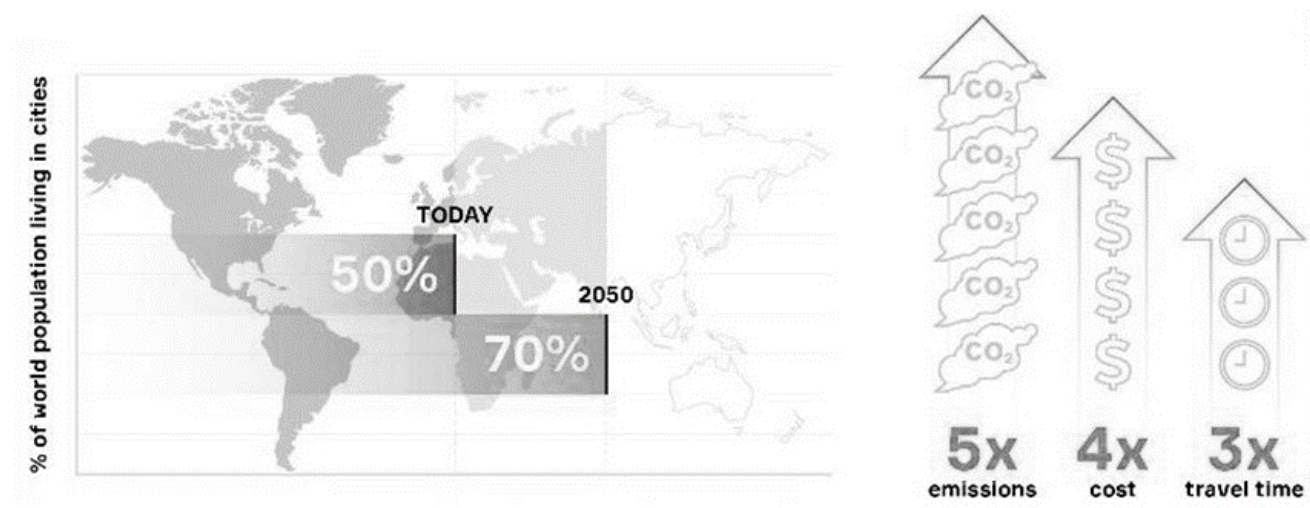

Figure 1. Percent of population living in cities [1]. 
The autonomous driving infrastructure includes everything from traffic cones to roadside sensors and smart signage. In smart cities of the future, connectivity is going to be more important than the fuel that vehicles use. Spearheading the smart city revolution, autonomous vehicles will bring a whole palette of sensors and IoT devices, while the advanced 5G network will enable them to receive, process, and transmit virtually unlimited amounts of data to modern urban environments. Experts argue that $5 \mathrm{G}$ might be the missing piece that will make efficient autonomous vehicles possible. The network is claimed to be up to a hundred times faster than $4 \mathrm{G}$, and by 2024, it is expected to be used in $40 \%$ of the world, Figure 2.

Recent analyses show that autonomous vehicles are capable of cutting urban travel time by a third and reducing greenhouse emissions by two thirds. For crowded metropolises of today, this means a reduction of vehicles for almost $30 \%$. Perhaps the more pressing issue of parking spaces would also be reduced by a staggering $40 \%$.

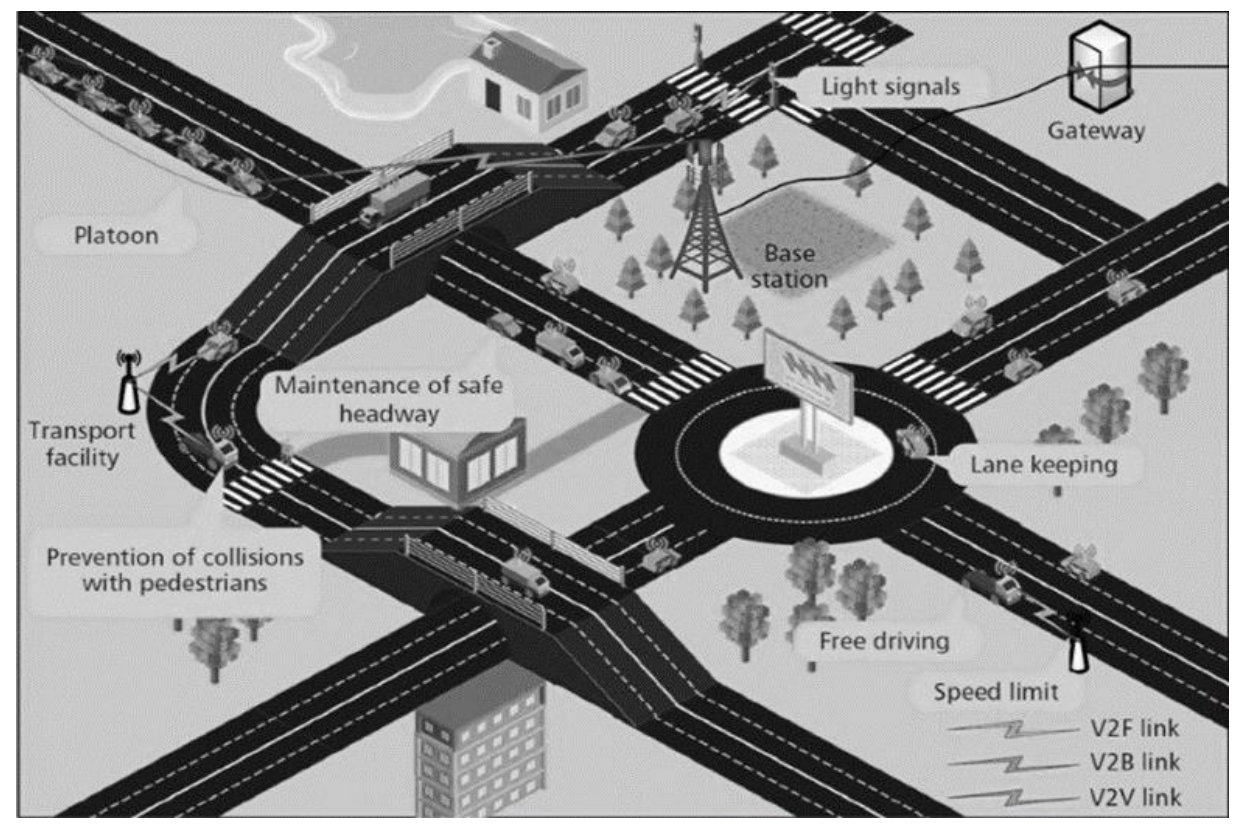

Figure 2. Smart city infrastructure [2].

\section{AUTONOMOUS DRIVING AND CONGESTION}

Even the behavior of a single driver can have a dramatic impact on hundreds of cars, making it more difficult to manage traffic. While the attempts to analyze and correct the traffic patterns that lead to congestion began as early in the 1930s, it was not until recently that scientists developed simulation techniques and advanced algorithms to create more realistic visualizations of traffic flow. In experiments conducted by Alexandre Bayen, Director for the Institute for Transportation Studies and the Liao-Cho Professor of Engineering at the University of California at Berkeley, which included several dozens of cars in a small-scale closed circuit, a single autonomous vehicle could eliminate traffic jams by moderating the speed of every car on the road [6-11].

In larger simulations, the research showed that once their number rises to 5-10\% of all cars in the traffic, they can manage localized traffic even in complex environments, such as merging multiple lanes of traffic into two or navigating extremely busy sections.

\section{REDUCED NUMBER OF CARS}

Autonomous driving technology is expected to reduce the number of cars on the road, the number of car movements, and the parking space requirements. Although this was partially 
achieved through car sharing, driverless cars would contribute by reducing car movements. New autonomous vehicles could also offer shared rides, however, if a large number of nondrivers decides to purchase their own autonomous cars, city cores will be congested with autonomous cars with far less capacity than public transports. This means that smart cities need to put more effort into increasing the efficiency of the number of people transported per hour, and not on autonomous vehicles as a single solution [12-14].

\section{FASTER COMMUTING TIMES}

The idea of bringing smart infrastructure and autonomous vehicles together is to improve the quality of life for citizens and help them navigate their urban environment in a faster and safer way. Deployed as an essential component of smart technology, the Internet of Things (IoT) enables different objects and systems to communicate with each other using wireless internet connection. The IoT will have a huge role in automated driving systems, as it is used to relay important traffic messages, provide real-time energy consumption, and to communicate with other driverless vehicles.

With smartphone applications for autonomous car-sharing, millions of people could avoid being packed like sardines in trains and buses every morning, only to get stuck in hour-long traffic jams. By interacting with digital road signage and mobile apps, autonomous vehicles would receive data on delays, traffic jams, and even accidents in real-time, so they can adjust their routes to reach the destination faster. With an integrated parking grid system, the driverless vehicle could navigate straight to the nearest vacant spot, eliminating both the emissions and cruising times, which add to the local traffic [15].

\section{ECONOMIC AND ENVIRONMENTAL BENEFITS}

With a widespread car autonomy, it is expected that car ownership will become less common. As long as the seamless service is provided, owning a car may not be as important. According to RethinkX think tank, driverless cars will be fleet-owned, perhaps even by their manufacturers. They also predict that by the year 2030, the demand for new cars will drop by $80 \%$. This conclusion is based on an estimate that the use of autonomous cars will increase at least tenfold, which means fewer vehicles on the road. When it comes to autonomous cars, fossil fuels are not as practical as electric power, and the new infrastructure needed to charge electric batteries and the associated technology will create many jobs for the increasing population. In this sense, smart cars will contribute to the general effort to limit the use of fossil fuels and adopt greener forms of transport with minimal carbon emissions (Fig. 3.).
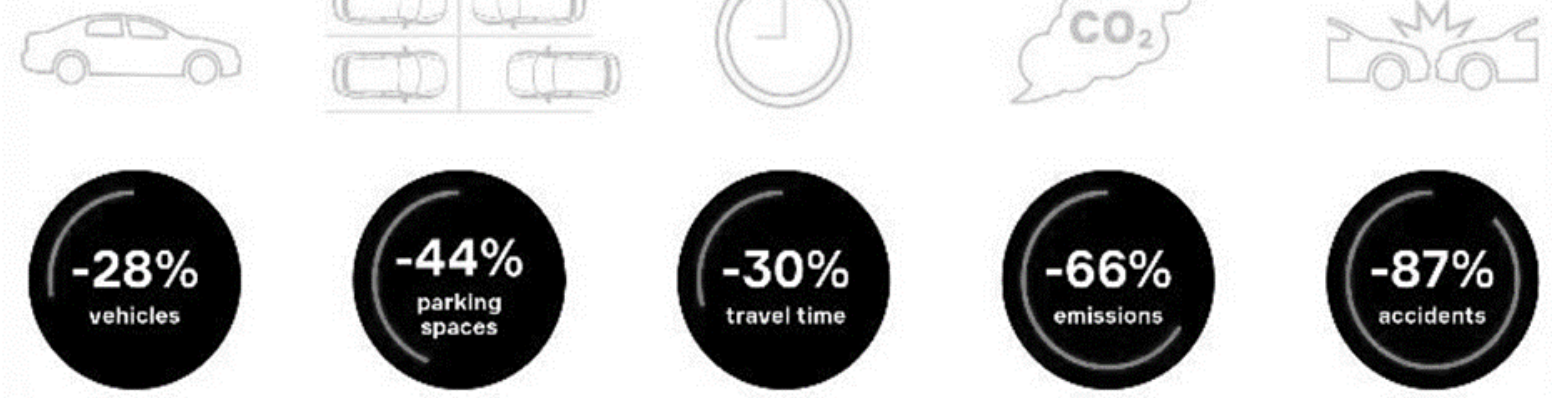

Figure 3. Economic and environmental benefits [3]. 


\section{CONCLUSION}

By investing in more systems that are able to communicate with autonomous vehicles through IoT platforms, smart cities would be able to solve upcoming issues even before they become problems, helping to allocate resources in such a way that maximizes the effectiveness of autonomous vehicles in reducing traffic, emissions, and in increasing road safety for all participants.

\section{REFERENCES}

[1] Pisarov, J.: $5 G$ and self-driving cars. In Croatian.

Proceedings TREND 2020, Kopaonik, pp.391-394, 2020,

[2] Mester, G.; Pletl, S.; Nemes, A. and Mester, T.: Structure Optimization of Fuzzy Control Systems by Multi-Population Genetic Algorithm.

Proceedings of the $6^{\text {th }}$ European Congress on Intelligent Techniques and Soft Computing, EUFIT'98, Aachen, 1, pp.450-456, 1998,

[3] Mester, G.: Cloud Robotics Model.

Interdisciplinary Description of Complex Systems 13(1), 1-8, 2015,

http://dx.doi.org/10.7906/indecs.13.1.1,

[4] Tokody, D.: Digitising the European Industry - Holonic Systems Approach.

Procedia Manufacturing 22, 1015-1022, 2018,

http://dx.doi.org/10.1016/j.promfg.2018.03.144,

[5] Tokody, D.; Albini, A.; Ady, L.; Temesvári, Z.M. and Rajnai, Z.: Cyber security in the automotive industry. In Hungarian.

Bánki Közlemények 1(3), 71-77, 2018,

[6] Rodic, A. and Mester, G.: Control of a Quadrotor Flight.

Proceedings of the ICIST Conference, Kaunas, pp.61-66, 2013,

[7] Mester, G. and Rodic, A.: Navigation of an Autonomous Outdoor Quadrotor Helicopter. Proceedings of the $2^{\text {nd }}$ International Conference on Internet Society Technology and Management, Koparnik, pp.259-262, 2012,

[8] Mester, G.: Backstepping Control for Hexa-Rotor Microcopter. Acta Technica Corviniensis-Bulletin of Engineering 8(3), 121-125, 2015,

[9] Mester, G.: Modeling of Autonomous Hexa-Rotor Microcopter.

Proceedings of the $3^{\text {rd }}$ International Conference and Workshop Mechatronics in Practice and Education, Subotica, pp.88-91, 2015,

[10] Mester, G.: New Trends in Scientometrics.

Proceedings of the $33^{\text {rd }}$ International Scientific Conference Science in Practice, Würzburg \& Schweinfurt, pp.22-27, 2015,

[11]Rodic, A.; Katic, D. and Mester, G.: Ambient Intelligent Robot-Sensor Networks for Environmental Surveillance and Remote Sensing.

Proceedings of the $7^{\text {th }}$ IEEE International Symposium on Intelligent Systems and Informatics, Subotica, pp.39-44, 2009,

[12] Rodic, A. and Mester, G.: Ambientally Aware Bi-Functional Ground-Aerial Robot-Sensor Networ-ked System for Remote Environmental Surveillance and Monitoring Tasks. Proceedings of the $55^{\text {th }}$ ETRAN Conference, Section Robotics, Teslić, pp.1-4, 2012,

[13]Kasac, J.; Milic, V.; Stepanic, J. and Mester, G.: A Computational Approach to Parameter Identification of Spatially Distributed Nonlinear Systems with Unknown Initial Conditions.

IEEE Symposium on Robotic Intelligence in Informationally Structured Space, pp.1-7, 2014,

[14] Albini, A.; Mester, G. and Iantovics, B.L.: Unified Aspect Search Algorithm. Interdisciplinary Description of Complex Systems 17(1-A), 20-25, 2019, http://dx.doi.org/10.7906/indecs.17.1.4,

[15] Mester, G.: Introduction to Control of Mobile Robots. Proceedings of the YUINFO'2006, Koparnik, pp.1-4, 2006. 